\title{
Converting a globus pallidus neuron model from 585 to 6 compartments using an evolutionary algorithm
} Eric Hendrickson*1, Jeremy Edgerton ${ }^{2}$, Cengiz Gunay ${ }^{2}$, Nathan Schultheiss ${ }^{2}$ and Dieter Jaeger ${ }^{2}$

Address: ${ }^{1}$ Department of Biomedical Engineering, Georgia Institute of Technology, Atlanta, GA 30332, USA and 2Department of Biology, Emory University, Atlanta, GA 30332, USA

Email: Eric Hendrickson* - eric.hendrickson@bme.gatech.edu

* Corresponding author

from Sixteenth Annual Computational Neuroscience Meeting: CNS*2007

Toronto, Canada. 7-12 July 2007

Published: 6 July 2007

BMC Neuroscience 2007, 8(Suppl 2):PI22 doi:10.1 186/147I-2202-8-S2-PI22

(c) 2007 Hendrickson et al; licensee BioMed Central Ltd.

\section{Background}

Biologically realistic neuron models are useful tools for understanding the behavior and mechanisms of neurons, but they are computationally expensive due to their fine granularity. This makes them unattractive for use in network simulations and generally leads to their replacement by simpler "integrate and fire" or black box models which are computationally cheaper, but further removed from biology. An attractive alternative is to replace a biologically realistic model with a 'reduced' version containing fewer compartments. This reduced model should largely preserve biological realism while limiting complexity and computational cost.

\section{Methods and results}

We present a 6 compartment 'reduced' model which preserves the electrotonic surface area distribution of a morphologically realistic 585 compartment globus pallidus 'full' model previously developed in the Jaeger Lab. Using an evolutionary algorithm, we searched the parameter space of the reduced model for values of $\mathrm{R}_{\mathrm{m}^{\prime}} \mathrm{R}_{\mathrm{a}^{\prime}}$ and $\mathrm{C}_{\mathrm{m}}$ which yield close matches to the passive properties of the full model. The passive fitness function is based on varying levels of current injection, at different locations, with different frequencies. Once our search was complete, we chose the values of $R_{m^{\prime}} R_{a^{\prime}}$ and $C_{m}$ that yield the best match with the passive properties of the full model. To match the active properties of the full model, we used an evolutionary algorithm to search the parameter space consisting of the various conductances shown in Table 1, along with their relative somatic and dendritic distributions. Our fitness function compares the FI curve, response to dendritic current injection, and various measures of spike shape. We tested approximately 120,000 different parameter sets, and the best (of many good fits) is shown in Table 1 and Figure 1. The fit between the full

Table I: Parameter sets which yield good matches to the full model.

\begin{tabular}{cccccccccc}
\hline Param Set & NaF & NaP & Kv2 & Kv3 & Kv4 & KCNQ & SK & Ca_HVA & IH \\
\hline Full Model & 350 & 1.015 & $\mathrm{I}$ & 11.25 & 20 & 2 & 4 & 0.3 & 0.2 \\
Reduced Model & 303.49 & 1.26 & 1.92 & 8.48 & 27.13 & 2.38 & 2.79 & 0.91 & 0.33 \\
\hline
\end{tabular}

Units of conductance are in $\mathrm{S} / \mathrm{m}^{2}$. $\{\mathrm{NaF}, \mathrm{NaP}\}$ fast, persistent sodium; $\{\mathrm{Kv} 2, \mathrm{Kv} 3, \mathrm{Kv} 4, \mathrm{KCNQ}\}$ voltage gated $\mathrm{K}+$ channel families; $\{\mathrm{SK}\}$ calciumactivated $\mathrm{K}+;\left\{\mathrm{Ca} \_\right.$HVA $\}$L-Type calcium; $\{\mathrm{IH}\}$ hyperpolarization activated current 

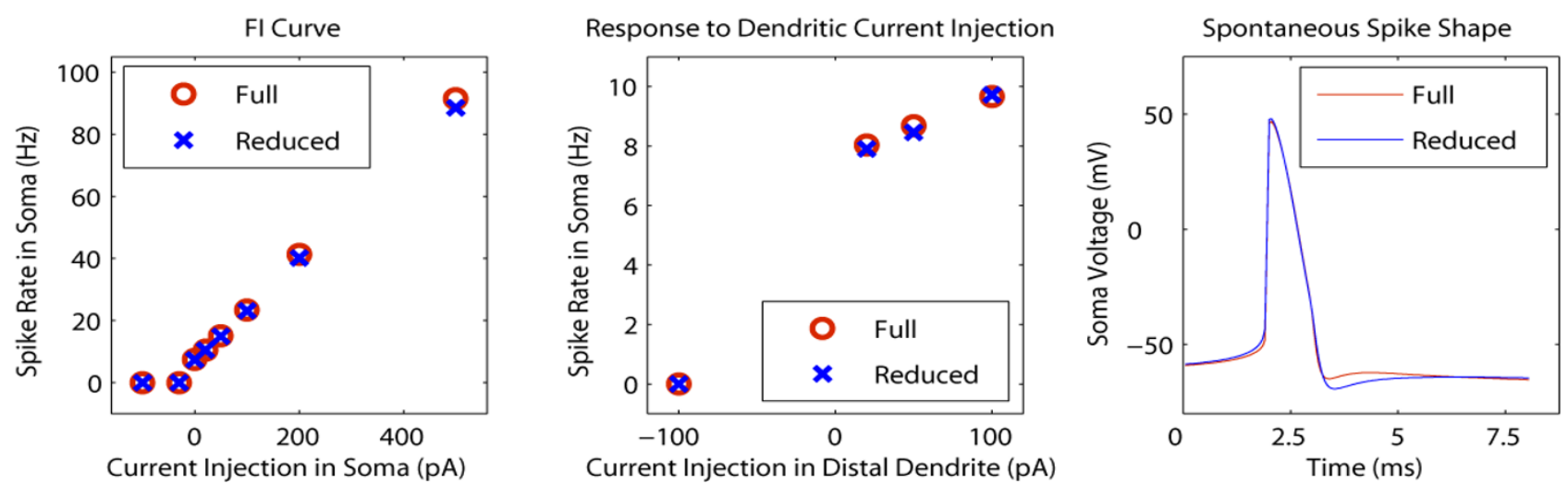

Figure I

Fit results. Full is the output trace from the full model, and Reduced is the output trace from the reduced model.

and reduced models is extremely good for the measures tested, with the exception of the afterhyperpolarization; we suggest that this may be due to differences in axial resistance. Further characterization of the parameter space is in progress.
Publish with Biomed Central and every scientist can read your work free of charge

"BioMed Central will be the most significant development for disseminating the results of biomedical research in our lifetime. " Sir Paul Nurse, Cancer Research UK

Your research papers will be:

- available free of charge to the entire biomedical community

- peer reviewed and published immediately upon acceptance

- cited in PubMed and archived on PubMed Central

- yours - you keep the copyright

Submit your manuscript here:

http://www.biomedcentral.com/info/publishing_adv.asp 